\title{
Validity Study of the Thinking Styles Inventory
}

\author{
Anne C. Black \\ Yale University \\ D. Betsy McCoach
University of Connecticut
}

This article examines the psychometric properties of the 104-item Thinking Styles Inventory (TSI; Sternberg \& Wagner, 1992) using responses from 789 students from 4 high schools in Connecticut. Twelve of the 13 subscales identified in mental self-government (MSG) theory (Sternberg, 1988, 1997) were included in all analyses. Both subscale- and item-level confirmatory factor analysis failed to confirm the theory-proposed 5-factor structure as well as 3 other structural models identified in previous studies. Post hoc item-level exploratory factory analysis and subscale score reliability analysis resulted in the omission of 64 original items due to weak psychometric properties. Thirty-two original items were retained, comprising 5 subscales, Liberal/ Progressive, External, Hierarchic, Judicial, and Legislative/Self-Reliant, largely consistent with those identified in MSG theory. Implications of the results are discussed.

Although by no means a new area of research in the field of education or psychology, the study of intellectual (cognitive, thinking, learning) styles continues to provide new information about their role in students' academic experiences that has implications for educational practice. For more than 5 decades, theorists have named and defined numerous categories of intellectual styles, a fairly comprehensive account Sternberg and Grigorenko $(1997,2001)$ provide. Over the past decade, one theory that has received considerable attention in educational research has been Sternberg's $(1988,1997)$ theory of mental self-government (MSG), which proposes that the organization of thinking parallels the organization of political government,

Anne C. Black is Associate Research Scientist in the Department of Psychiatry at Yale University School of Medicine, where she works with a research team in studying the efficacy of specific behavioral interventions for individuals with substance use issues and dual diagnoses. D. Betsy McCoach is Associate Professor in the University of Connecticut's Measurement, Evaluation and Assessment program, where she teaches coursework in educational statistics, measurement, and research design.

Journal for the Education of the Gifted. Vol. 32, No. 2, 2008, pp. 180-210. Copyright @2008 Prufrock Press Inc., http://www.prufrock.com 
and that individuals govern themselves according to their personal thinking styles or, more accurately, their own profiles of thinking styles. Thinking style has been defined as the "interface between intelligence and personality" (Sternberg, 1994, p. 169), and as “... a favored way of expressing or using one or more abilities" (Grigorenko \& Sternberg, 1997, p. 297). The construct has been operationalized by the Thinking Styles Inventory (TSI; Sternberg \& Wagner, 1992), a 104-item survey that assesses individuals' preferences on each of 13 styles. This article examines the psychometric properties of that instrument in order to determine the accuracy with which the construct MSG thinking styles has been measured and thus the extent to which research related to that construct should be regarded as wellfounded.

The term style, as regards human intellect, refers to "habitual patterns or preferred ways of doing something... that are consistent over long periods of time and across many areas of activity" (Sternberg \& Grigorenko, 2001, p. 2). Style is differentiated from ability, a term referring to "things one can do-a skill or skill combinations" (Zhang, 2001, p. 622). MSG theory proposes that thinking styles comprise five dimensions that are analogous to facets of government: function, form, level, scope, and leaning (Sternberg, 1997; see Table 1).

\section{MSG Dimensions of Thinking Style}

The three functions of mental self-government are legislative, executive, and judicial. Briefly, legislative thinkers enjoy creating their own rules for doing things, and prefer to decide for themselves what things to do and how to do them. Executive thinkers, conversely, prefer to follow established rules and value problems that are prestructured. People with a preference for a judicial style of thinking favor analyzing and evaluating existing rules and procedures and critiquing the work of others (Sternberg, 1997).

There are four forms of mental self-government: monarchic, hierarchic, oligarchic, and anarchic (Sternberg, 1997). The monarchic person is described as "single minded and driven" (Sternberg, 1997, p. 22), focusing exclusively on tasks or activities of interest. The hierarchic person is able to prioritize among goals and 


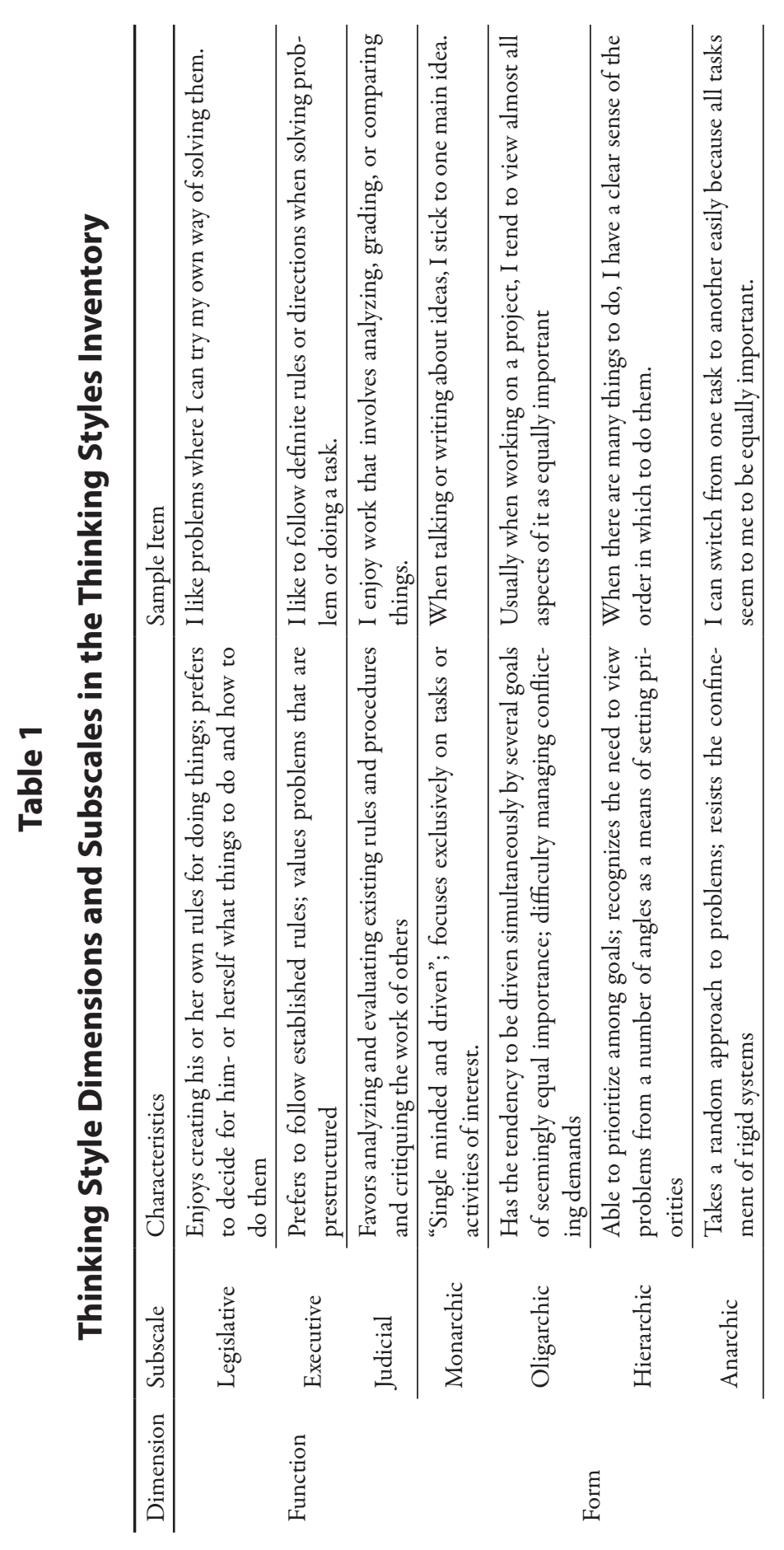




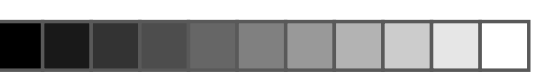

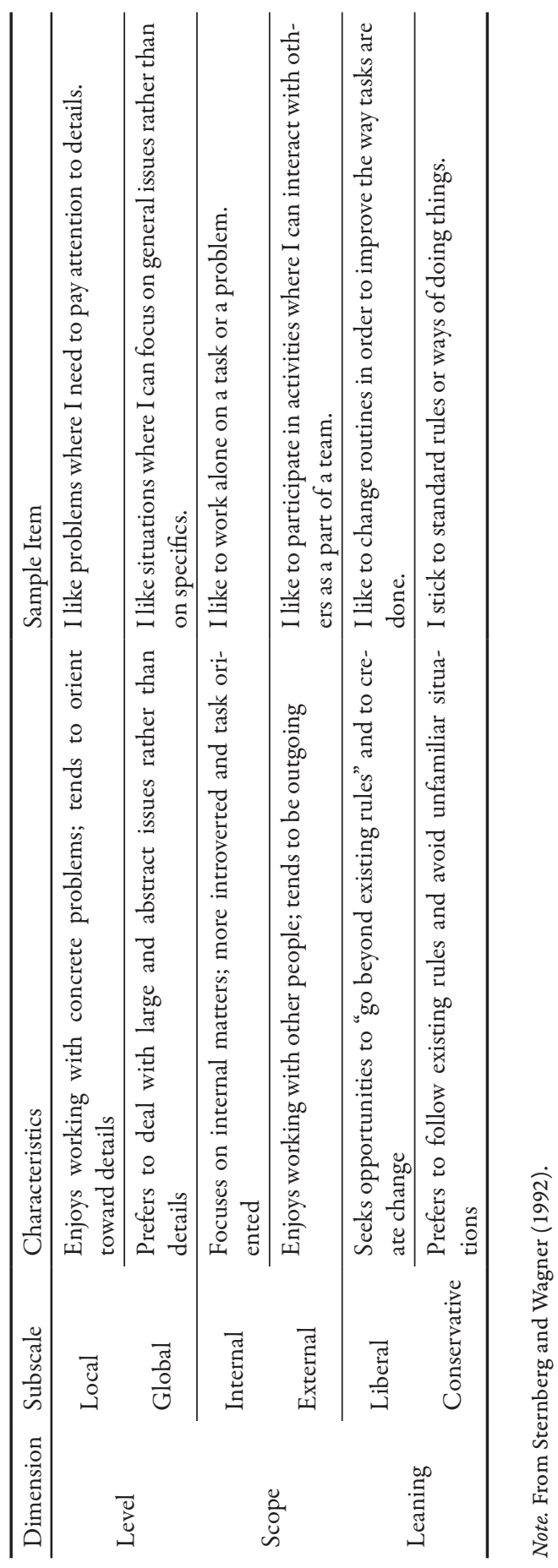


"recognizes the need to view problems from a number of angles" (Sternberg, 1997, p. 23) as a means of setting priorities. To be oligarchic in thinking is to have the tendency to be driven simultaneously by several goals of seemingly equal importance with difficulty managing the conflicting demands. Lastly, the anarchic individual seems to take a random approach to problems, resisting the confinement of rigid systems.

In terms of levels, global thinkers prefer to deal with large and abstract issues rather than details while local thinkers enjoy working with concrete problems and tend to orient toward details (Sternberg, 1997).

Having an internal scope of mental self-government involves focusing on internal matters. Individuals who favor an internal style are more introverted, task oriented, and perhaps less socially sensitive than are external people. While internal-style individuals prefer to work alone, externals enjoy working with other people and tend to be outgoing (Sternberg, 1997).

Leanings refer to individual tendencies to embrace or eschew change. Liberal individuals seek opportunities to "go beyond existing rules" (Sternberg, 1997, p. 26) to create change, and may become bored easily. Conservatives tend to prefer to follow existing rules and avoid unfamiliar situations. Individuals favoring this thinking style will create structure in environments where structure is lacking (Sternberg, 1997).

MSG theory asserts that people possess profiles of styles rather than single styles (Sternberg, 1997). A profile is composed of some combination of the elemental styles within the five MSG dimensions. A thinking style profile is made up of several favored styles. For example, a student may favor both legislative and internal styles, indicating a preference both to rely on her own ideas and strategies for solving a problem and to work independently. Further, and perhaps most intriguing, is the proposition that thinking styles are socialized and teachable, variable according to task and situation, and, to some degree, flexible (Sternberg, 1997). Although an attractive notion, this seems to conflict with the very nature of styles as being "habitual patterns ... that are consistent over long periods of time ..." (Sternberg \& Grigorenko, 2001, p. 2). Nonetheless, some degree of empirical support for the socialization of styles has been claimed. 


\section{Social and Academic Correlates of MSG Thinking Styles}

Sternberg and Grigorenko (1995) used correlational analysis to illustrate "at least a suggestion" that students' thinking styles may be socialized by their teachers (p. 213) and reported significant correlations between some thinking styles and socioeconomic status (SES), as estimated by parent education (viz., executive style, $r=-.43$; with judicial style, $r=-.23$; and with conservative style, $r=-.47$; p. 212) and as estimated by father education only (viz., legislative style, $r=.36$ and with hierarchic style, $r=.25)$. Additional support was declared by Zhang and Postiglione (2001) who, after controlling for student age, found weak but statistically significant correlations between some thinking styles and SES indicators. Those partial correlations ranged from $r=.08$ (global style and father's education level) to $r=$ .12 (hierarchic style and family income). In addition to considering the size of the reported correlation coefficients, the critical reader also should note that causal relationships were not established in these studies. That is, neither differences in teachers' thinking styles nor differences in students' family SES was determined to cause differences in students' thinking styles.

Other studies have reported associations between thinking style and academic achievement (Bernardo, Zhang, \& Callueng, 2002; Cano-Garcia \& Hewitt Hughes, 2000; Zhang, 2000, 2002a) as well as interactions between thinking styles and types of academic assessment (Sternberg \& Grigorenko, 1993), between students' and teachers' thinking styles (Sternberg \& Grigorenko, 1995), and between thinking styles and academic subject (Zhang, 2001, 2004) that have implications for students' academic performance. Some studies have called upon educators to revise instructional and assessment strategies to accommodate students of varying thinking styles (Sternberg \& Grigorenko, 1993, 1995; Zhang, 2000).

The measurement and application of thinking styles have been advocated within the gifted education literature (Dai \& Feldhusen, 1999; Sternberg \& Grigorenko, 1993). Sternberg and Grigorenko suggested that thinking styles are likely moderator variables that may help to distinguish different subgroups of gifted children. They maintain that thinking styles may explain preferences for independence or guided instruction and individual work or cooperative group work. 
Further, they suggest that thinking styles may inform the nature of assessment used for identification of giftedness, and thinking style should be considered when making decisions between educational enrichment and acceleration options (Sternberg \& Grigorenko, 2003). However intuitively appealing these recommendations may be, primary consideration must be given to the reliability and validity of the measurement of the thinking styles construct. The savvy consumer of any such research should first ask, "How well has this construct been measured?"

\section{Measurement of MSG Thinking Styles}

The 13 thinking styles that compose the five dimensions proposed in MSG theory are operationalized by the TSI (Sternberg \& Wagner, 1992), a 104-item scale with eight questions targeting each style. Individuals rate the eight items within each subscale from 1-7 indicating how well each statement describes them, where $1=$ not at all well and $7=$ extremely well. A mean subscale rating that is close to 7 is a high score and is interpreted as a preference for that thinking style. Mean ratings closer to 1 are interpreted as "low" ratings for that subscale and indicate a lack of preference for that style (Sternberg, 1997). Thinking style profiles are identified by the TSI in terms of how high or low respondents' mean scores are on each of the 13 thinking style subscales. A profile is the combination of all subscales on which the rater indicates a preference.

Variations of the TSI include an expanded item rating scale (1-9 vs. 1-7) and a shortened, 65-item version (General Thinking Styles Inventory-Short Version, unpublished) consisting of 5 items for each of the 13 subscales.

Although Sternberg (1997) claimed that the TSI has "demonstrated good psychometric properties" (p. 125), studies using scores on the TSI have returned varying results in terms of subscale score reliability (coefficient alpha). All have indicated a wide range of estimates across the 13 subscales (see Table 2). With the full 104-item scale for four subgroups of students divided by grade (grades $7 \& 8$, $9 \& 10,11 \& 12$, and college) and one group of "laypeople," subscale score reliabilities ranged from .35 to .88 across groups, with mean reli- 


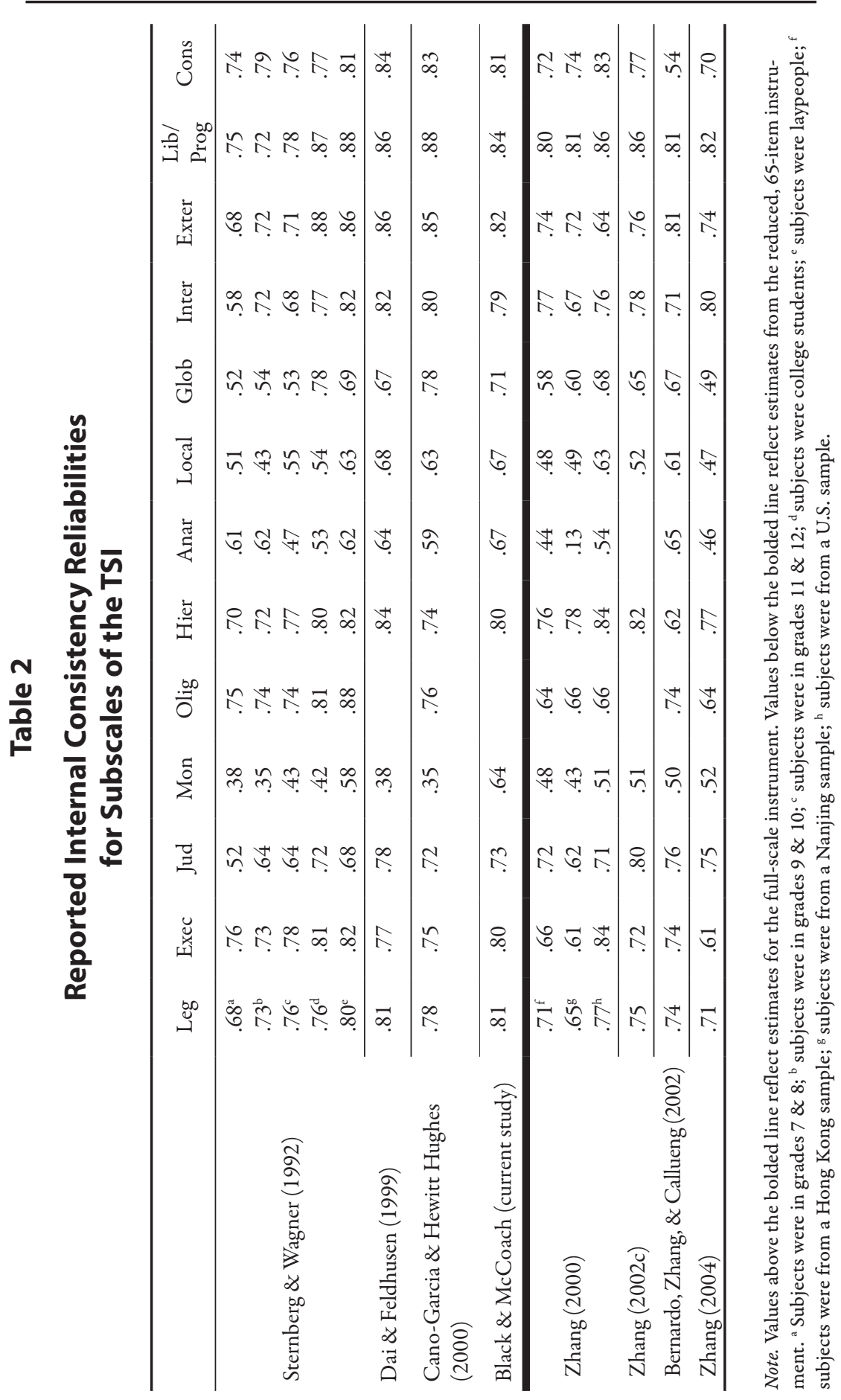


ability estimates ranging from .63 (grades $7 \& 8$ ) to .76 (laypeople; Sternberg \& Wagner, 1992). Other reported alpha reliability ranges for scores obtained with the full-scale instrument were .38-.86 (Dai \& Feldhusen, 1999) and .35-.88 (Cano-Garcia \& Hewitt Hughes, 2000). Studies using the 65 -item inventory have reported similar alpha reliability ranges of .46-.82 (Zhang, 2004); .51-.86 (Zhang 2002c); .44-.80, .13-.81, .50-.86 (Zhang, 2000); and .50-.81 (Bernardo et al., 2002). Although there is no universally accepted minimum estimate for the internal consistency coefficient, Charter (2003) presented many proposed guidelines in a review of literature on the topic. Minimum alpha values of .80 to .90 are the most common among those recommendations. According to Charter, "The ideal of an internal consistency reliability of .90 or .95 may be difficult to attain in many cases, but test constructors should strive to give clinicians good tools to work with" (p. 302).

In addition, the factor structure of the subscales of the TSI has not been clearly established, with factor analysis failing to fully support the dimensionality proposed by MSG theory (Sternberg \& Grigorenko, 1993) and with other factor analytic studies reporting inconsistent factor structures across samples (see, for example, Bernardo et al., 2002; Cano-Garcia \& Hewitt Hughes, 2000; Dai \& Feldhusen, 1999; Fjell \& Walhovd, 2004; Zhang \& Sachs, 1997; see Table 3). "If the factor structure of a measure cannot be replicated from sample to sample, its usefulness is diminished, perhaps to the point where its construct validity is called into question" (Steger, 2006, p. 263).

Moreover, we have found no reported item-level factor analysis on the full-scale TSI. Although a confirmatory factor analysis (CFA) of the 24 items composing the three MSG Functions was conducted by O'Hara and Sternberg (2000-2001; results of which indicated poor model fit; $\chi^{2}(255, N=105)=548, p<.001$; goodness of fit index $=$ $.71)$, our review of the literature revealed that all factor analyses conducted on the full-scale instrument involved subscale-level data.

\section{Rationale for Study}

The current study is unique in its goal to identify the factor structure of TSI scores for high school aged students using item-level data. 
Table 3

Factor Structures of the TSI Reported in Six Studies

\begin{tabular}{|c|c|c|c|c|c|}
\hline & Factor 1 & Factor 2 & Factor 3 & Factor 4 & Factor 5 \\
\hline $\begin{array}{l}\text { Initial Study } \\
\text { (see Sternberg } \\
\text { \& Grigorenko, } \\
\text { 1993) }\end{array}$ & $\begin{array}{l}\text { Conservative } \\
\text { Executive } \\
\text { Progressive (-) } \\
\text { Legislative (-) }\end{array}$ & $\begin{array}{l}\text { Judicial } \\
\text { Oligarchic }\end{array}$ & $\begin{array}{l}\text { External } \\
\text { Internal (-) }\end{array}$ & $\begin{array}{l}\text { Local } \\
\text { Global (-) }\end{array}$ & Hierarchic \\
\hline $\begin{array}{l}\text { Zhang \& Sachs, } \\
1997\end{array}$ & $\begin{array}{l}\text { Conservative } \\
\text { Executive } \\
\text { Oligarchic } \\
\text { Monarchic }\end{array}$ & $\begin{array}{l}\text { Legislative } \\
\text { Judicial }^{\dagger} \\
\text { Local } \\
\text { Liberal }^{\dagger} \\
\text { Anarchic } \\
\text { Internal }\end{array}$ & $\begin{array}{l}\text { Judicial }^{\dagger} \\
\text { Liberal }^{\dagger} \\
\text { Hierarchical } \\
\text { External }\end{array}$ & & \\
\hline $\begin{array}{l}\text { Dai \& } \\
\text { Feldhusen, } 1999\end{array}$ & $\begin{array}{l}\text { Legislative } \\
\text { Liberal } \\
\text { Anarchic } \\
\text { Judicial } \\
\text { Internal }^{\dagger} \\
\text { Local }^{-}\end{array}$ & $\begin{array}{l}\text { Executive } \\
\text { Conservative } \\
\text { Monarchic } \\
\text { Hierarchic }\end{array}$ & $\begin{array}{l}\text { Internal }(-)^{\dagger} \\
\text { External } \\
\text { Global }\end{array}$ & & \\
\hline $\begin{array}{l}\text { Cano-Garcia \& } \\
\text { Hewitt Hughes, } \\
2000\end{array}$ & $\begin{array}{l}\text { Progressive } \\
\text { Judicial } \\
\text { Anarchic } \\
\text { Conservative }^{\dagger} \\
\text { External }^{\dagger} \\
\text { Legislative }^{\dagger}\end{array}$ & $\begin{array}{l}\text { Executive } \\
\text { Conservative }^{\dagger} \\
\text { Hierarchic } \\
\text { Monarchic }^{\dagger} \\
\text { Oligarchic }^{\dagger}\end{array}$ & $\begin{array}{l}\text { Internal } \\
\text { External }(-)^{\dagger} \\
\text { Legislative }^{\dagger} \\
\text { Oligarchic }(-)^{\dagger}\end{array}$ & $\begin{array}{l}\text { Monarchic } \\
\text { Global } \\
\text { Local (-) }\end{array}$ & \\
\hline $\begin{array}{l}\text { Bernardo, } \\
\text { Zhang, \& } \\
\text { Callueng, } 2002\end{array}$ & $\begin{array}{l}\text { Legislative } \\
\text { Judicial }^{\dagger} \\
\text { Global } \\
\text { Liberal } \\
\text { Anarchic } \\
\text { Internal }^{\dagger}\end{array}$ & $\begin{array}{l}\text { Executive } \\
\text { Judicial }^{\dagger} \\
\text { Local } \\
\text { Conservative } \\
\text { Hierarchic } \\
\text { Monarchic } \\
\text { Oligarchic }^{\dagger}\end{array}$ & $\begin{array}{l}\text { Oligarchic }^{\dagger} \\
\text { Internal }(-)^{\dagger} \\
\text { External }\end{array}$ & & \\
\hline $\begin{array}{l}\text { Fjell \& } \\
\text { Walhovd, } 2004 \\
\text { Norwegian } \\
\text { Sample }\end{array}$ & $\begin{array}{l}\text { Judicial } \\
\text { Hierarchic } \\
\text { Liberal } \\
\text { Legislative }^{\dagger}\end{array}$ & $\begin{array}{l}\text { Legislative }^{\dagger} \\
\text { Executive } \\
\text { Conservative } \\
\text { Monarchic }\end{array}$ & $\begin{array}{l}\text { Anarchic } \\
\text { Oligarchic }\end{array}$ & $\begin{array}{l}\text { External } \\
\text { Internal }\end{array}$ & $\begin{array}{l}\text { Local } \\
\text { Global }\end{array}$ \\
\hline $\begin{array}{l}\text { Fjell \& } \\
\text { Walhovd, } 2004 \\
\text { Texas Sample }\end{array}$ & $\begin{array}{l}\text { Judicial } \\
\text { Hierarchic }^{\dagger} \\
\text { Liberal } \\
\text { Legislative }\end{array}$ & $\begin{array}{l}\text { Executive } \\
\text { Conservative } \\
\text { Monarchic } \\
\text { Local }\end{array}$ & $\begin{array}{l}\text { Hierarchic }^{\dagger} \\
\text { Anarchic } \\
\text { Oligarchic }\end{array}$ & $\begin{array}{l}\text { External } \\
\text { Internal }\end{array}$ & Global \\
\hline
\end{tabular}

Note. Subscales with coefficients $\geq .40$ are listed when provided. Otherwise, the factor structure is reproduced as reported in the article. ${ }^{\dagger}$ Subscale loaded on more than one factor. ${ }^{(-)}$Negative factor loading. 
The study used CFA to compare the adequacy and fit of competing hypothesized structural models and used posthoc exploratory factor analysis (EFA) to examine further the data structure. A second purpose of the study was to determine whether the TSI could be reduced to a shorter, psychometrically stronger inventory that provides a reliable measure of MSG thinking styles.

\section{Methods}

In this study, scores on the 104-item TSI were collected from 790 students in grades 9-12 in four high schools in Connecticut. One case was removed due to substantial missing data, resulting in 789 cases. For the remaining cases, the amount of missing data ranged from .25\% to $3.80 \%$ per variable. Four-hundred seventy-seven cases contained complete data and 222 different patterns of missingness existed for the remaining cases. There was no reason to believe data were missing by any systematic process, and we assumed the data to be missing at random (MAR), an assumption that is, in many cases "quite plausible" (Schafer \& Graham, 2002, p. 152). In order to retain all cases for analysis, data augmentation with single imputation of estimates for missing values ${ }^{1}$ was used with NORM 2.03 software (Schafer, 2000). This resulted in 789 cases with completed (observed and simulated) data for 12 of the 13 subscales (96 of the 104 total items). Because different items were inadvertently used to measure the oligarchic style with some of the students (see Oligarchic items in Sternberg \& Wagner, 1992, vs. Sternberg, 1997), that 8-item subscale was omitted from all analyses.

TSI subscale score reliabilities were estimated with SPSS 14.0 software and compared to previous studies. We then conducted CFAs of both scale- and item-level data with AMOS 6.0 to determine whether the MSG theory-specified model structure (Sternberg, 1988, 1997) fit the data collected from this high school sample. Three other proposed structures also were specified using both subscale- and item-level data for comparison of model fit; one model specifying the threefold model of intellectual styles with three factors indicated by Type I, Type II, and Type III styles (Zhang 2006; Zhang $\&$ Sternberg, 2005); the second specifying two factors made up of 
Type I and Type II styles (Zhang, 2002a, 2002b), and the third specifying the four-factor structure reported by Zhang (2006). Item-level EFA was subsequently conducted with SPSS 14.0 to examine further the latent structure accounting for the covariances among variables in the data set (Brown, 2006). Finally, Cronbach's alpha internal consistency reliabilities were estimated for the subscales composed of retained items.

\section{Data Screening}

As an initial screening of the data, the distributions of items were examined for univariate normality. In addition, bivariate and squared multiple correlations among the 12 subscales were reviewed as indicators of multicollinearity, and variances of subscales were examined for relative size. Subscale score internal consistency reliability estimates also were assessed (Kline, 2005). All items were distributed normally (absolute value of skewness index $\leq 3.0$, absolute value of kurtosis index $\leq 10.0$; Kline, 2005). Absolute values of the bivariate correlations among subscales ranged from $r=.02$ (Liberal-Conservative) to $r=.65$ (Liberal-Legislative), and no squared multiple correlation was larger than $R^{2}=.61$, signifying nonredundancy among subscales. Subscale variances were homogeneous, ranging from .74 to 1.27 . However, reliability estimates for some subscale scores (Monarchic, Anarchic, and Local) were lower than .70, a generally recommended value for "adequate" reliability (Kline, 2005).

\section{Results}

\section{Internal Consistency Reliability Analysis}

Internal consistency reliabilities for scores on the original 12 TSI subscales were estimated for comparison to previous studies. Our estimates were higher in comparison, ranging from .64 (Monarchic) to .84 (Liberal). However, in addition to reporting Cronbach's alpha, which is solely a function of the interrelatedness of items 


\section{Table 4}

\section{Internal Consistency Reliabilities, Standard Errors, and Interitem Correlations for 12 of the Original 13 Subscales of the TSI}

\begin{tabular}{lccccc}
\hline \multicolumn{1}{c}{ Subscale } & $\begin{array}{c}\text { Coefficient alpha } \\
(\text { SE })\end{array}$ & Mean IIC & $\begin{array}{c}\text { Minimum } \\
\text { IIC }\end{array}$ & $\begin{array}{c}\text { Maximum } \\
\text { IIC }\end{array}$ & $\begin{array}{c}\text { Std Dev of } \\
\text { IIC }\end{array}$ \\
\hline Anarchic & $.67(.014)$ & .204 & .003 & .336 & .071 \\
Conservative & $.81(.020)$ & .350 & .142 & .571 & .105 \\
Executive & $.80(.016)$ & .331 & .141 & .534 & .084 \\
External & $.82(.024)$ & .364 & .119 & .617 & .126 \\
Global & $.71(.025)$ & .244 & -.042 & .465 & .130 \\
Hierarchic & $.80(.012)$ & .330 & .218 & .472 & .063 \\
Internal & $.79(.019)$ & .320 & .131 & .571 & .100 \\
Judicial & $.73(.023)$ & .252 & .021 & .441 & .118 \\
Legislative & $.81(.015)$ & .340 & .177 & .512 & .077 \\
Liberal & $.84(.019)$ & .392 & .218 & .637 & .100 \\
Local & $.67(.011)$ & .206 & .107 & .388 & .055 \\
Monarchic & $.64(.017)$ & .185 & .063 & .485 & .089 \\
\hline
\end{tabular}

Note. IIC $=$ Interitem correlations, $\mathrm{SE}=$ standard error.

in the subscale and test length and not of scale unidimensionality (Schmitt, 1996), it is recommended that the "precision of alpha" also be reported (Cortina, 1993, p. 100), providing an indication of the spread of interitem correlations (IIC). Both precision of alpha estimates and standard deviations of IIC were calculated for all subscales (see Table 4).

A large spread of correlations "indicates either some form of multidimensionality or a great deal of sampling error in the estimation of the interitem correlations" (Schmitt, 1996, p. 351).

Anarchic, Local, and Monarchic subscales had particularly weak mean IIC $(.20, .21$, and .19 , respectively) while Conservative, External, Global, Internal, Judicial, and Liberal subscales had large IIC ranges with relatively unstable alpha estimates $\left(\mathrm{SD}_{\text {IIC }} \geq .100\right.$; $\left.\mathrm{SE}_{\text {alpha }} \geq 0.019\right)$. These statistics are indicative of errors in the operationalization of the proposed constructs that also were evident in the factor analyses. 
Subscale-Level CFA

The first subscale-level CFA tested the five-factor model specified by MSG theory (Sternberg, 1988, 1997) with forms, function, level, scope, and leaning identified as latent variables causing the variance in scores on each of their respective style indicators (omitting oligarchic as an indicator variable of the Function factor). Factor 1, Forms, was indicated by Legislative, Executive, and Judicial subscales. Factor 2, Function, was indicated by Anarchic, Monarchic, and Hierarchic subscales. Factor 3, Level, was indicated by Global and Local subscales. Factor 4, Scope, was indicated by Internal and External subscales. Factor 5, Leaning, was indicated by Liberal and Conservative subscales. Correlations between all factor pairs were specified. Because a sample variance was estimated to be zero or negative, no model solution could be estimated. Negative variance estimates are indicative of some form of model misspecification (Kline, 2005). To test a more parsimonious model, an equality constraint was then applied to the respective paths of the three factors with only two indicator variables. This respecification did not improve model fit, and no solution could be estimated for this revised model. One source of misspecification of the five-factor model was the specification of weakly correlated pairs of indicators for Factor 4 (Internal and External; $r=-.11$ ) and Factor 5 (Liberal and Conservative; $r=$ .02 ), with the bivariate correlation for the latter pair not statistically significantly different from zero (see Table 5$)$.

Next the three-factor Type model (Zhang \& Sternberg, 2005) was fit to the data, specifying Legislative, Judicial, Hierarchic, Global, and Liberal styles as indicators of Type I; Executive, Local, Monarchic, and Conservative styles as indicators of Type II; and Anarchic, Internal, and External styles as indicators of Type III. The result was an inadmissible solution, with the correlation between Type I and Type III factors estimated to be greater than 1.0 and the variance-covariance matrix for the first-order factors not positivedefinite.

Then we estimated the fit of the two-factor Type model (Zhang, 2002a, 2002b) with Factor 1, Type I, causing Legislative, Judicial, Hierarchic, Global, and Liberal variables and Factor 2, Type II, causing Executive, Local, Monarchic, and Conservative variables. The 


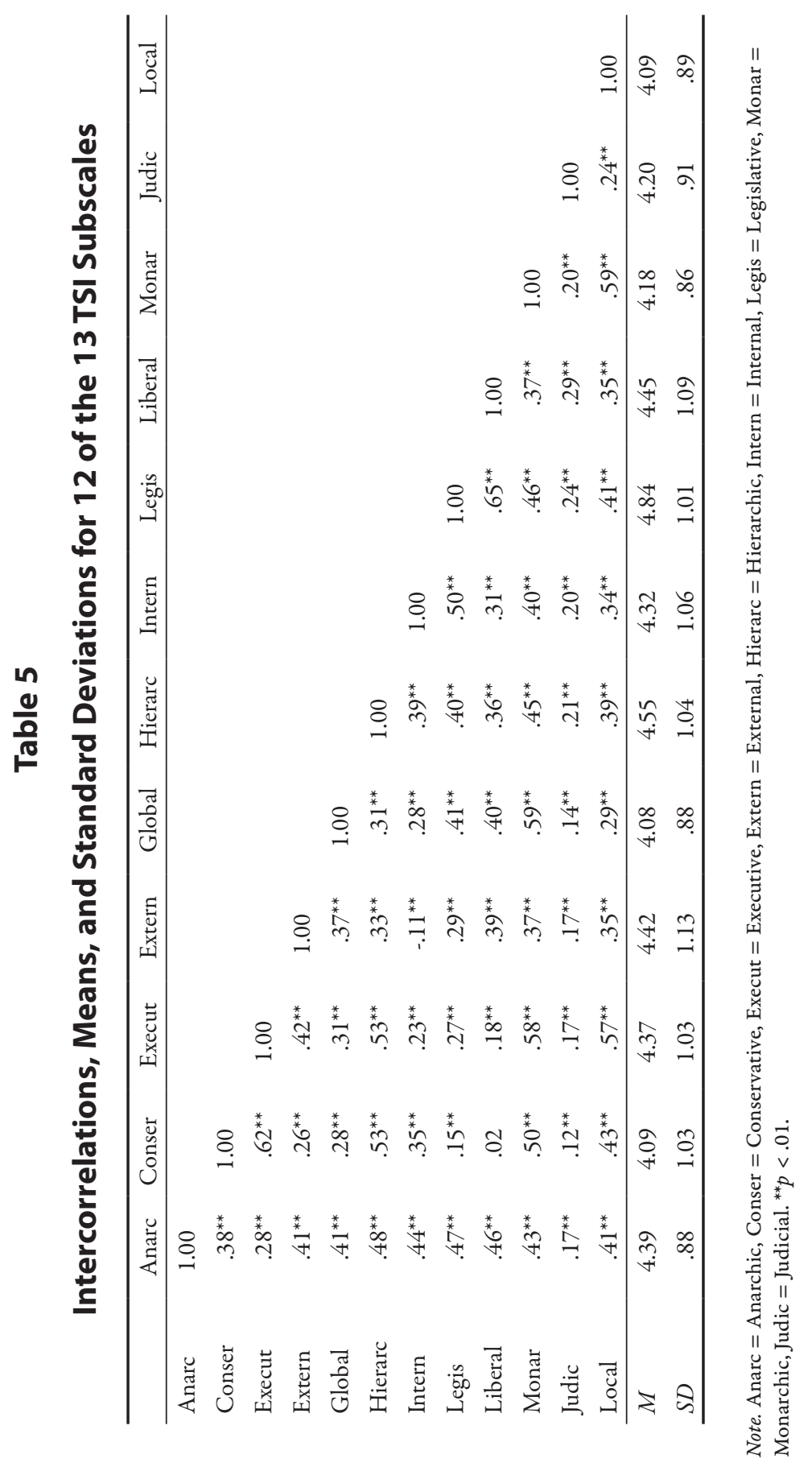


result indicated poor fit of the model to the data $\left(\chi^{2}[26]=653.29\right.$; $p<.001$; CFI $=.779$; RMSEA $=.175$ [90\% C.I. $=.164$, .187]; PCLOSE <.001). Large modification indices suggested correlating several uniquenesses with latent variables, correlating uniqueness pairs, and double-loading subscale indicators on both factors.

Finally we tested the four-factor model (Zhang, 2006) with Factor 1, Type 1, indicated by Legislative, Liberal, and Judicial subscales; Factor 2, Type II, indicated by Executive, Conservative, and Monarchic subscales; Factor 3, Level, indicated by Global and Local subscales, and Factor 4, Scope, indicated by Internal and External subscales. For this model, as with the five-factor model, a sample variance was estimated to be zero or negative, and no model solution could be estimated.

\section{Item-Level CFA}

The same four models were then estimated with item-level data. These models were hierarchical, with Dimension or Type factors serving as second-order factors and subscale factors as first-order factors, each indicated by their respective eight items (see Sternberg \& Wagner, 1992). In each model, all second-order factor pairs were specified to be correlated. Disturbances were added to all first-order factors and their respective paths were set to 1.0.

The hierarchical five-factor model (Sternberg, 1988) was estimated first. In this model, there were 5 second-order factors, Forms, Function, Level, Scope, and Leaning. Forms was indicated by 3 first-order factors, Legislative, Executive, and Judicial. Function also was indicated by 3 first-order factors, Anarchic, Monarchic, and Hierarchic. Level was indicated by 2 first-order factors, Global and Local. Scope was indicated by 2 first-order factors, Internal and External. Finally, Leaning was indicated by 2 first-order factors, Liberal and Conservative. All first-order factors were indicated by the eight measured variables that correspond with those subscales in the TSI. The result of this CFA was the same as with subscale-level data; a sample variance was estimated to be zero or negative, and no model solution could be estimated.

Next, the hierarchical three-factor Type model (Zhang, 2006; Zhang \& Sternberg, 2005) was specified. In this model, Type I, Type 
II, and Type III were specified as second-order factors. The firstorder factors indicating Type I were Legislative, Judicial, Hierarchic, Global, and Liberal. Indicating Type II were first-order factors Executive, Local, Monarchic, and Conservative. Anarchic, Internal, and External first-order factors were indicators of the second-order Type III factor. All first-order factors were indicated by the eight observed variables that correspond with those subscales in the TSI. The result of this CFA was the same as with the subscale-level data: The solution was inadmissible, with the correlation between Type I and Type III factors estimated to be greater than 1.0 and the variancecovariance matrix for the first-order factors not positive-definite.

The hierarchical two-factor Type model (Zhang, 2002a, 2002b) was then specified. In this model, there were 2 second-order factors, Type I and Type II. The former was indicated by 5 first-order factors, Legislative, Judicial, Hierarchic, Global, and Liberal, whereas the latter was indicated by 4 first-order factors, Executive, Local, Monarchic, and Conservative. All first-order factors were indicated by the eight observed variables that correspond with those subscales in the TSI. The result indicated poor fit of the model to the data $\left(\chi^{2}[2474]=8000.128 ; p<.001 ;\right.$ CFI $=.696$; RMSEA $=$ .053 [90\% C.I. $=.052, .055] ;$ PCLOSE $<.001)$. The standardized regression weight and model-implied correlation between Type II and Monarchic was .994, suggesting redundancy between those second- and first-order factors. Large modification indices suggested correlating several disturbances with first-order factors, correlating uniquenesses with latent variables, and double-loading indicator variables.

Finally, the four-factor model (Zhang, 2006) was specified with item-level indicators. This model had 4 second-order factors, Type I, indicated by Legislative, Liberal, and Judicial first-order factors; Type II, indicated by Executive, Conservative, and Monarchic first-order factors; Level, indicated by Global and Local first-order factors; and Scope, indicated by Internal and External first-order factors. All firstorder factors were indicated by the eight observed variables that correspond with those subscales in the TSI. The result was the same as with subscale-level data; a sample variance was estimated to be zero or negative, and no model solution could be estimated. 
Item-Level EFA

Subsequent to CFA in which a model is "grossly misspecified," EFA may be conducted to reassess the structure of the measurement model (Brown, 2006, p. 189). Given the failure of CFA to confirm any of the four proposed models with either scale- or item-level data, an item-level EFA of 12 of the 13 subscales (omitting Oligarchic) in the full-scale TSI was then conducted using SPSS 14.0 software. Because some subscale pairs have been determined to correlate significantly (see Sternberg \& Grigorenko, 1993), we used the principal axis factoring extraction option, selecting the extraction of factors with eigenvalues $>1.0$, with direct oblimin rotation. Scree plot, parallel analysis, amount of variance explained by each factor, and consistency with the theoretical model informed the extraction decision (Kim \& Mueller, 1978; Thompson, 2004). Scree plot visual analysis (Cattell, 1978) indicated the extraction of four factors, and parallel analysis indicated the extraction of nine factors. The first 4 factors accounted for only $31 \%$ of the total variance, whereas nine factors accounted for $43 \%$ of the variance. Given the greater percentage of variance accounted for with a nine-factor solution and the closer agreement of this solution with Sternberg's proposed model of 13 factors, a nine-factor solution was specified for extraction, and the patterns of coefficients resulting from that solution were analyzed. In addition to item content, weak pattern coefficients on primary factors $(<.350)$ and/or coefficients on secondary and subsequent factors of magnitude similar to the primary coefficient informed the decision to retain items. Forty-four of the 96 items, subsumed by six factors, met the criteria for retention (see Table 6).

Internal consistency reliability analysis of subscale scores was then conducted. As coefficient alpha is the quantification of the "degree of interrelatedness among a set of items designed to measure a single construct" (Netemeyer, Bearden, \& Sharma, 2003), items weakly correlated with other items in the subscale were determined to be poorly related to the construct and were removed. This process resulted in the omission of 12 additional items. Ultimately, all items from the Executive, Monarchic, Anarchic, Global, Local, and Conservative subscales were eliminated. Seven items from the Internal subscale, three items from the Judicial subscale, two items 


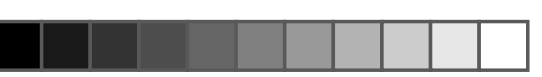

$\oplus$

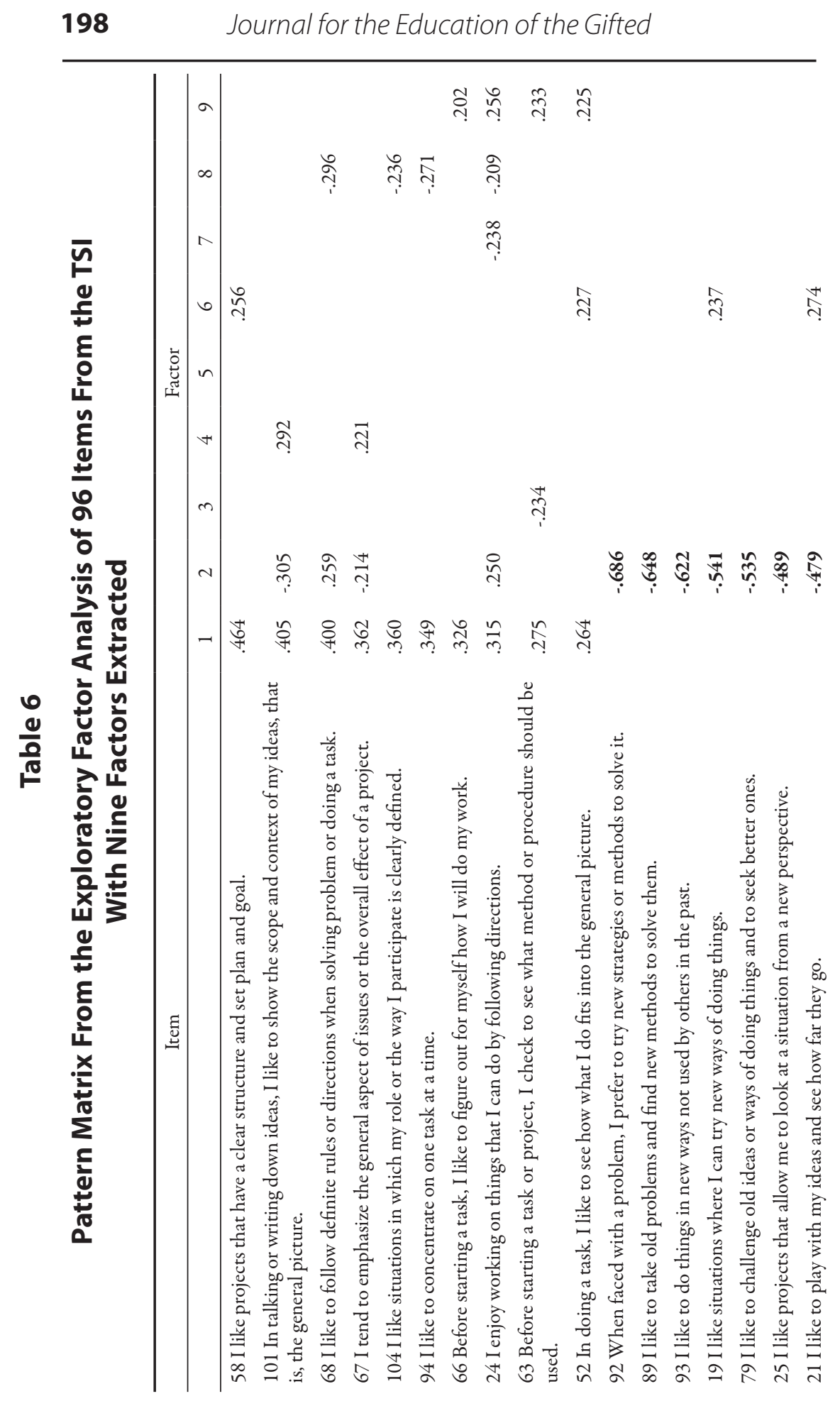



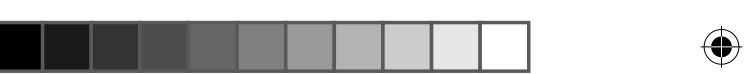

TSI Validity Study

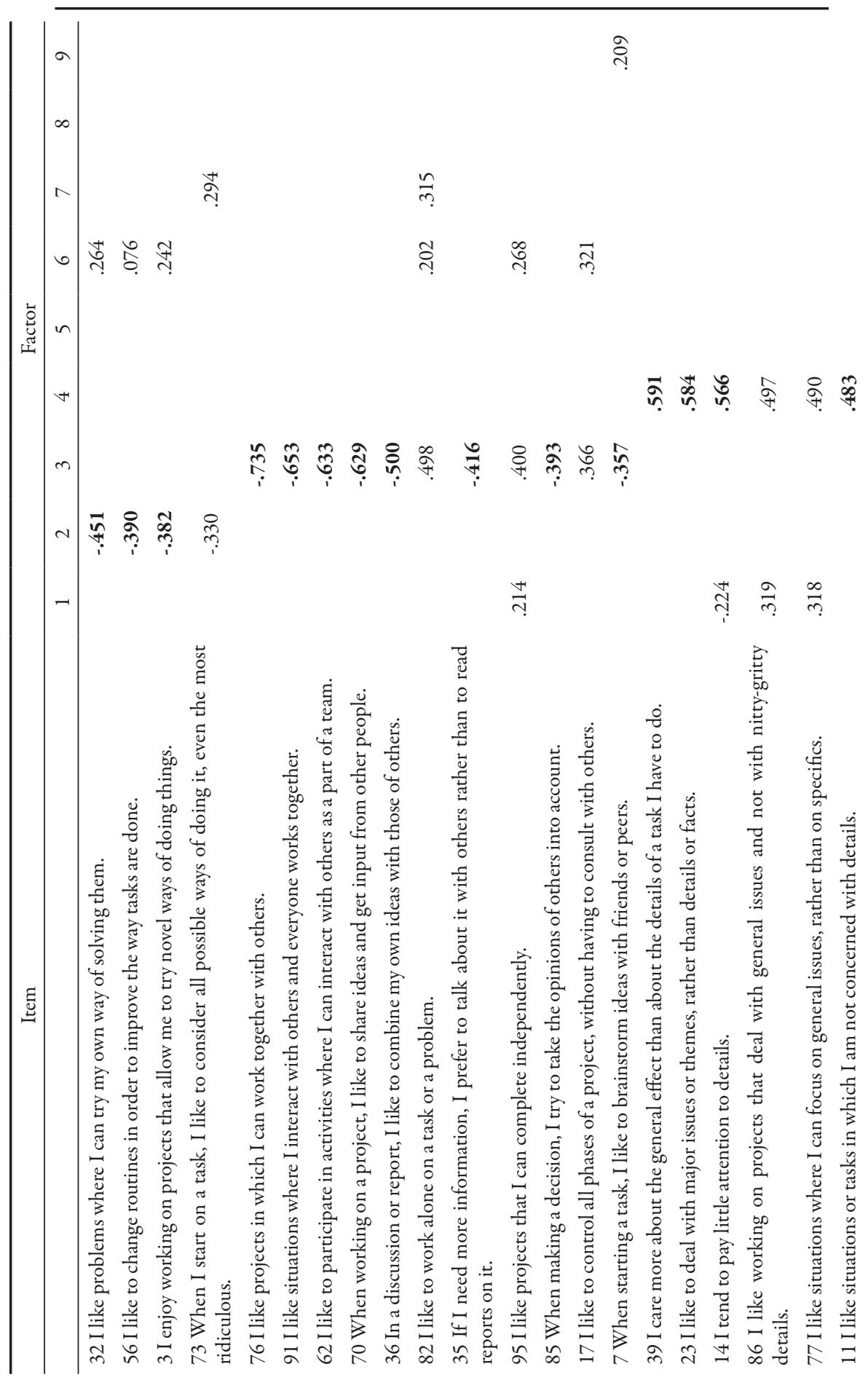



Journal for the Education of the Gifted

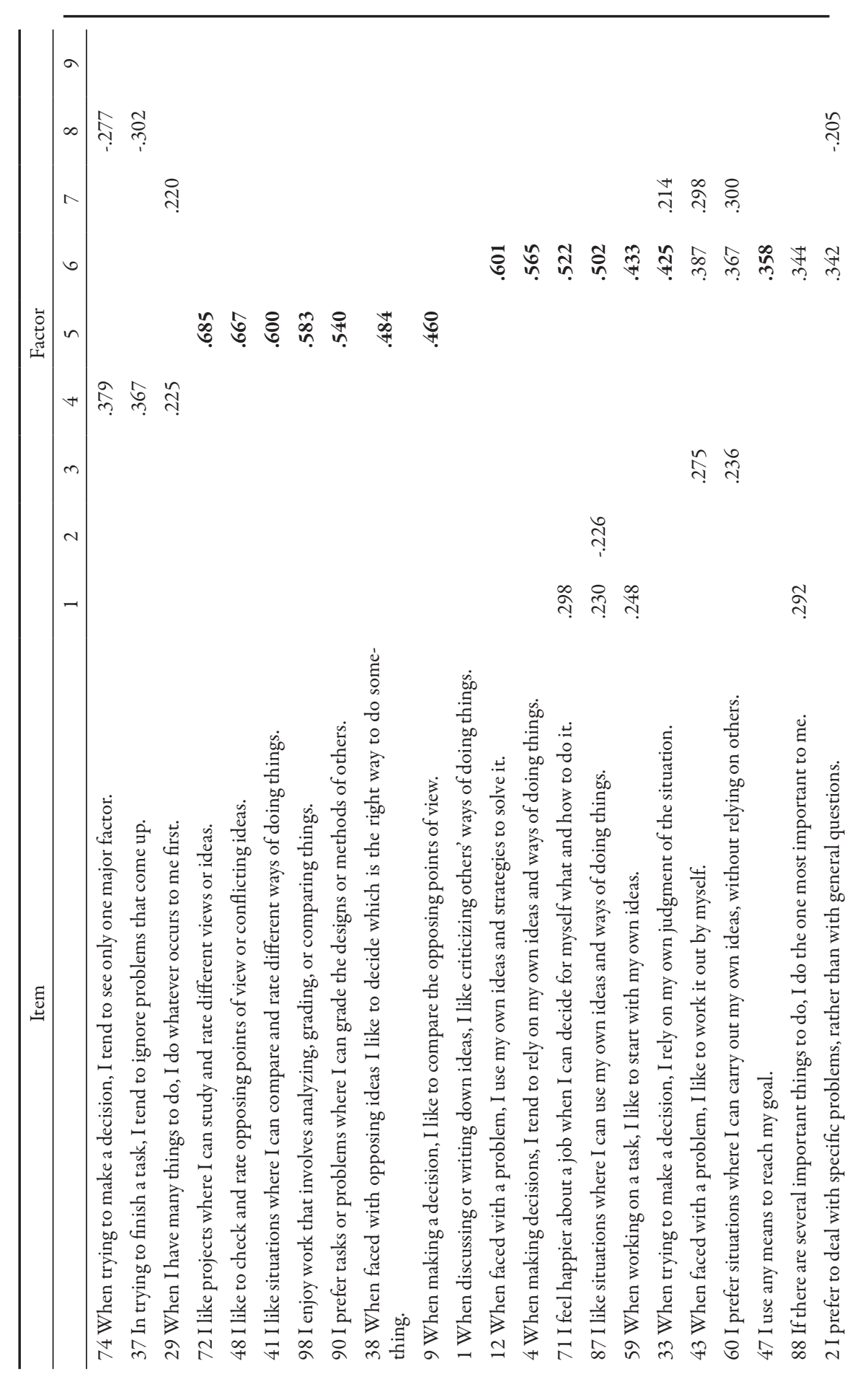



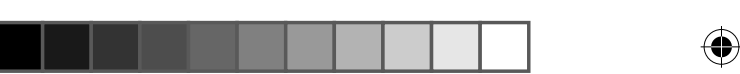

TSI Validity Study

201

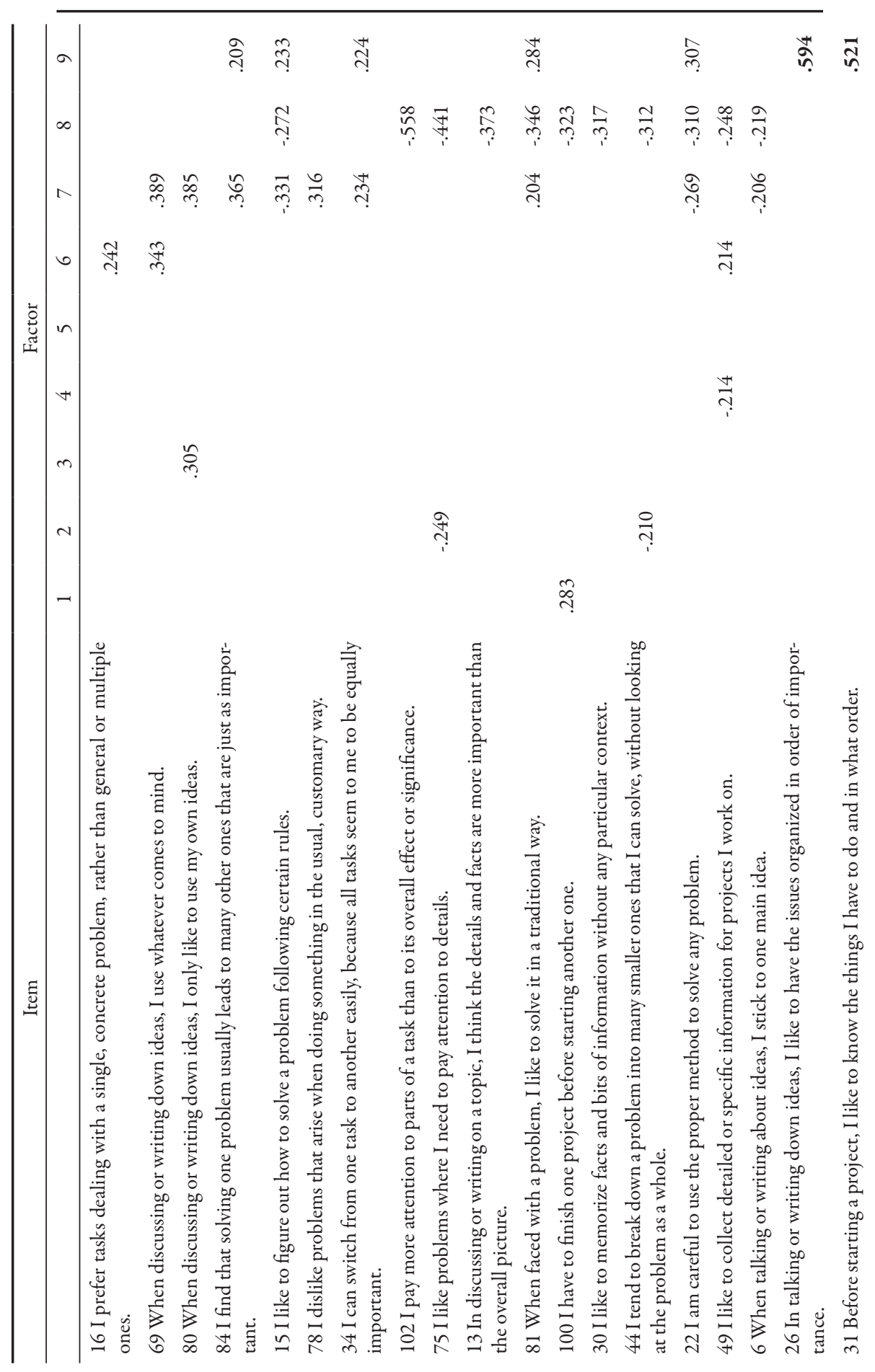




\section{2}

Journal for the Education of the Gifted

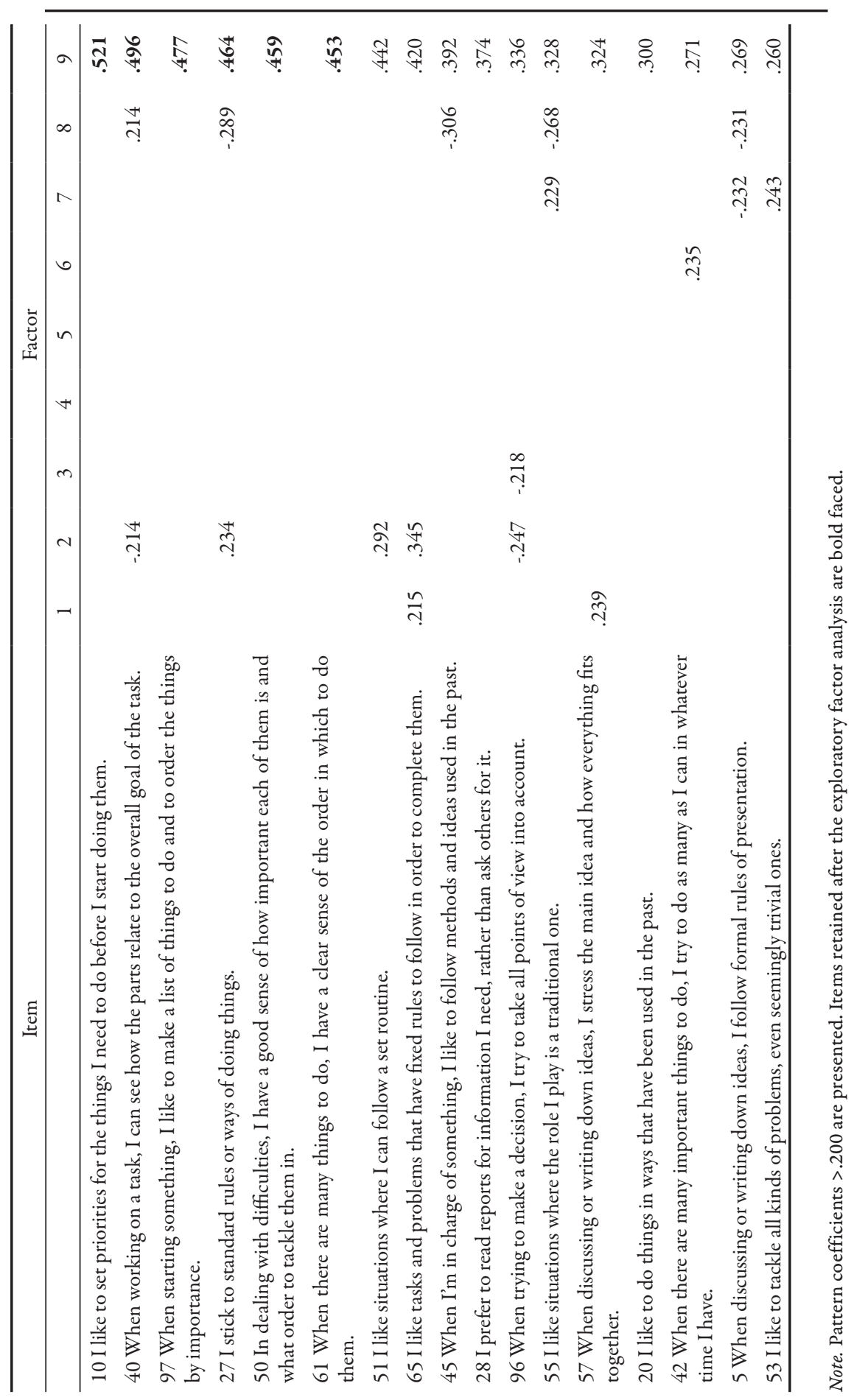


each from the Hierarchic and External subscales, and one item from both the Legislative and Liberal subscales were removed. This process resulted in the retention of 32 items subsumed by five factors with internal consistency reliabilities ranging from .729 to .863 (see Tables 7 and 8). Mean IIC within subscales were moderate, ranging from .35 (Judicial) to .45 (External), with standard deviations $\leq .10$.

Generally, items within the remaining original subscales loaded together on a common factor, with some items from related subscales also loading with those factors. The first subscale, for example, contains seven of the original Liberal items and two Legislative items. (The correlation between those two original subscales was reported to be .66. See Sternberg \& Grigorenko, 1993). The items in the new subscale combine to measure a Liberal/Progressive approach to thinking, with a preference for trying new methods and finding new strategies to solve problems. The second factor contains seven items exclusively from the original External subscale, measuring individuals' preferences for working and sharing ideas with others as outlined in MSG theory. Factor 3 subsumes six items from the original Hierarchic subscale. This factor measures the degree to which individuals prefer to order ideas and things to do by perceived importance. Factor 4 contains five Judicial items describing a propensity toward comparing and rating ideas or views. Finally, Factor 5 contains five Legislative and one Internal item, combining to measure individuals' reliance on their own ideas and strategies when doing a task (Legislative/Self-Reliant). Correlations between subscales were weak to moderate and positive with the strongest correlation $(r=$ .56) between Liberal and Legislative subscales and the weakest $(r=$ .16) between Hierarchic and Judicial subscales (see Table 9).

\section{Discussion}

Our study failed to provide statistical support for the use of the full-scale TSI as an instrument for the operationalization of MSG thinking styles with high school students. Although internal consistency reliability analysis of subscales returned alpha estimates that were larger than previous reports, interitem correlations within some 


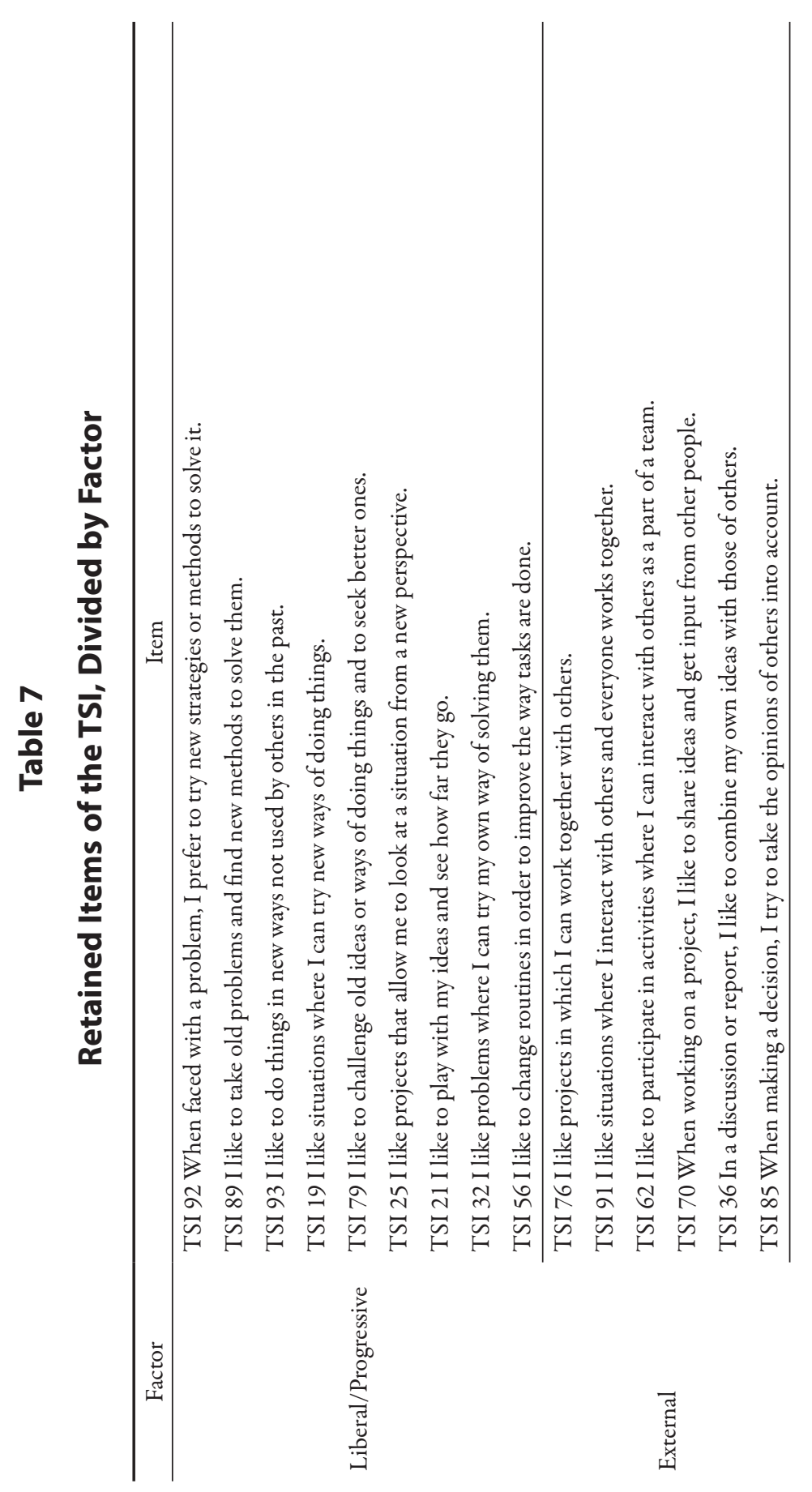



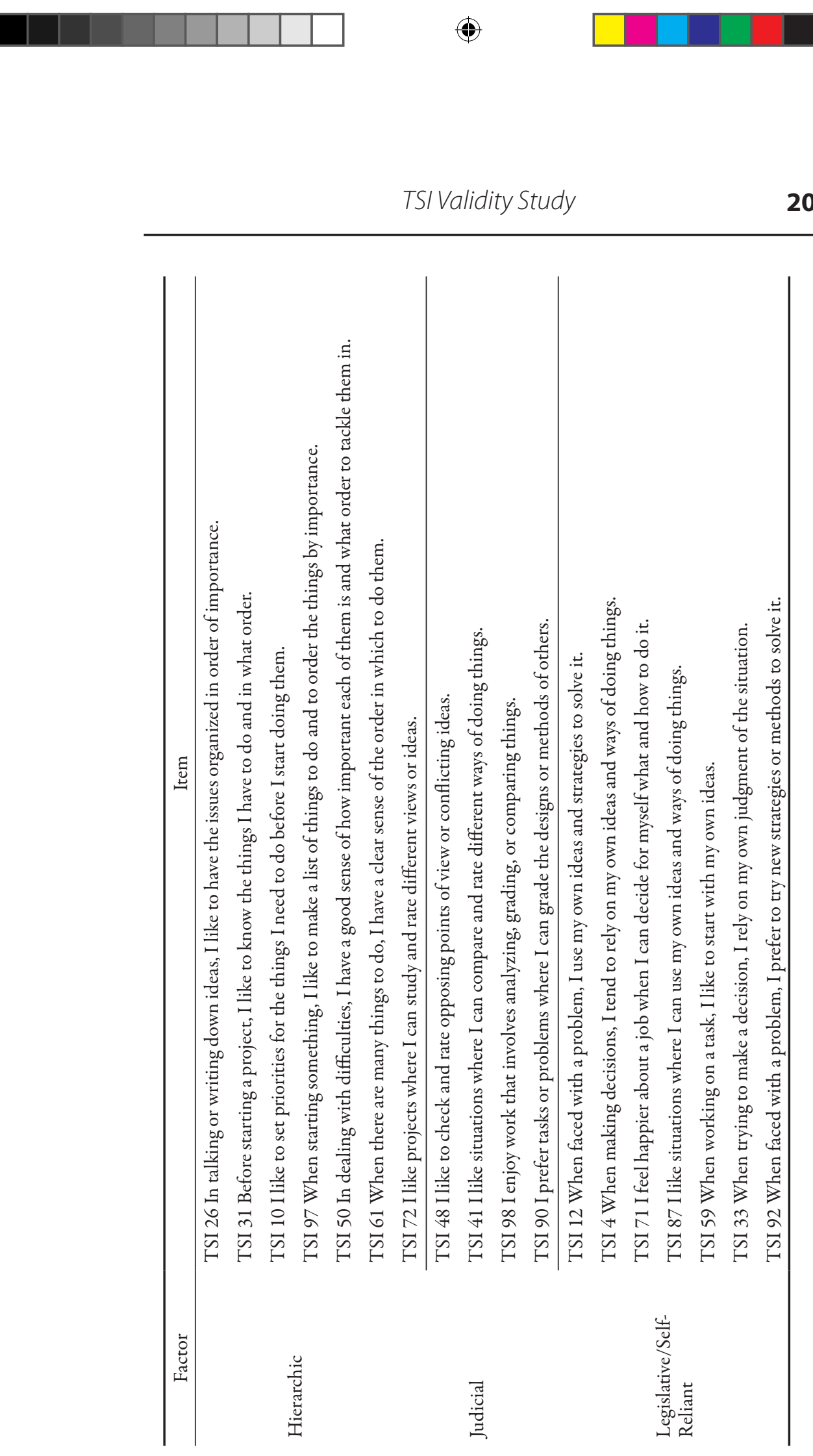


\section{Table 8}

\section{Internal Consistency Reliabilities of the Five Factors Subsuming the Retained 32 Items of the TSI}

\begin{tabular}{|c|c|c|c|c|c|c|}
\hline Subscale & $\begin{array}{l}\text { Number } \\
\text { of Items }\end{array}$ & $\begin{array}{l}\text { Coefficient } \\
\text { alpha (SE) }\end{array}$ & Mean IIC & $\begin{array}{c}\text { Minimum } \\
\text { IIC }\end{array}$ & $\begin{array}{l}\text { Maximum } \\
\text { IIC }\end{array}$ & $\begin{array}{c}\text { Std Dev of } \\
\text { IIC }\end{array}$ \\
\hline $\begin{array}{l}\text { Liberal/ } \\
\text { Progressive }\end{array}$ & 9 & $.863(.013)$ & .412 & .305 & .638 & .077 \\
\hline External & 6 & $.832(.027)$ & .448 & .285 & .617 & .100 \\
\hline Hierarchic & 6 & $.767(.015)$ & .355 & .278 & .472 & .055 \\
\hline Judicial & 5 & $.729(.024)$ & .351 & .249 & .439 & .071 \\
\hline $\begin{array}{l}\text { Legislative/ } \\
\text { Self-Reliant }\end{array}$ & 6 & $.778(.021)$ & .368 & .243 & .512 & .077 \\
\hline
\end{tabular}

Note. $\mathrm{SE}=$ Standard Error, IIC = Interitem correlations.

subscales were weak and varied, suggesting substantial measurement error. Neither scale- nor item-level CFA confirmed any of four purported latent structures of scores, revealing poor model fit or inadmissible solutions for the specified models. While a combination of item-level EFA and reliability analysis led to the identification of 32 relatively strong items that loaded on factors similar to those proposed by MSG theory, the scope of the remaining items does not sufficiently account for the theorized range of thinking styles as outlined by Sternberg $(1988,1997)$, nor does it provide a readily interpretable reduction in proposed styles. What may be considered a useful result of the EFA is the identification of items that are psychometrically strong, which may provide the basis for the development of an improved inventory of thinking styles. The study suggests that some items from the Liberal and Legislative, and Legislative and Internal subscales are conceptually similar and share common variance, indicating common latent structure among items in those subscales. This is consistent with EFA results from previous studies (Bernardo et al., 2002; Cano-Garcia \& Hewitt Hughes, 2000; Fjell \& Walhovd, 2004; Sternberg \& Grigorenko, 1993; Zhang \& Sachs, 1997).

The first goal of the study was met to the extent that we were able to specify the latent structure of the strongest items in the TSI and to identify and omit those items that did not meet standard psychomet- 
ric criteria. The second goal was partially met in the identification and retention of several original items whose structure was consistent with MSG theory that may serve as a basis for the creation of a meaningful and reliable tool for the measurement of thinking styles.

The results of this study are limited to scores from a single sample of high school students from four high schools in Connecticut. In addition, only 12 of the 13 subscales were included in the analysis, and the psychometric properties of the Oligarchic subscale were not determined with this sample. The reported factor structures accounted for only 96 of the 104 items in the TSI. Nonetheless, the study contributes to a continually developing pattern of evidence highlighting the weaknesses in the current operationalization of MSG thinking styles. This collection of evidence brings into question the validity of the claims of previous research regarding the role of thinking styles in students' academic experiences, and calls upon researchers and practitioners to be fully considerate of these psychometric weaknesses when making important educational decisions based upon such research. If educational practice is to be influenced by the notion of students' thinking styles, we must first insist upon improved standards of measurement of that construct.

\section{References}

Bernardo, A. B. I., Zhang, L. F., \& Callueng, C. M. (2002). Thinking styles and academic achievement among Filipino students. The Journal of Genetic Psychology, 163, 149-163.

Brown, T. A. (2006). Confirmatory factor analysis for applied research. New York: Guilford Press.

Cano-Garcia, F., \& Hewitt Hughes, E. (2000). Learning and thinking styles: An analysis of their interrelationship and influence on academic achievement. Educational Psychology, 20, 413-430.

Cattell, R. B. (1978). The scientific use of factor analysis. New York: Plenum.

Charter, R. A. (2003). A breakdown of reliability coefficients by test type and reliability method, and the clinical implications of low reliability. The Journal of General Psychology, 130, 290-304. 
Cortina, J. M. (1993). What is coefficient alpha? An examination of theory and applications. Journal of Applied Psychology, 78, 98-104.

Dai, D. Y., \& Feldhusen, J. F. (1999). A validation study of the Thinking Styles Inventory: Implications for gifted education. Roeper Review, 21, 302-307.

Fjell, A. M., \& Walhovd, K. B. (2004). Thinking styles in relation to personality traits: An investigation of the Thinking Styles Inventory and NEO-PI-R. Scandinavian Journal of Psychology, 45, 293-300.

Grigorenko, E. L., \& Sternberg, R. J. (1997). Style of thinking, abilities, and academic performance. Exceptional Children, 63, 295-312.

Kim, J., \& Mueller, C. W. (1978). Factor analysis: Statistical methods and practical issues. Newbury Park, CA: Sage.

Kline, R. B. (2005). Principles and practice of structural equation modeling (2nd ed.). New York: Guilford Press.

Netemeyer, R. G., Bearden, W. O., \& Sharma, S. (2003). Scalingprocedures. Thousand Oaks, CA: Sage.

O’Hara, L. A., \& Sternberg, R. J. (2000-2001). It doesn't hurt to ask: Effects of instructions to be creative, practical, or analytical on essay-writing performance and their interaction with students thinking styles. Creativity Research Journal, 13, 197-210.

Schafer, J. L. (November, 2000). NORM for Windows 95/98/NT (Version 2.03) [Computer software]. Retrieved March 15, 2005, from http://www.stat.psu.edu/ jls/misoftwa.html\#ack

Schafer, J. L., \& Graham, J. W. (2002). Missing data: Our view of the state of the art. Psychological Methods, 7, 147-177.

Schmitt, N. (1996). Uses and abuses of coefficient alpha. Psychological Assessment, 8, 350-353.

Steger, M. F. (2006). An illustration of issues in factor extraction and identification of dimensionality in psychological assessment data. Journal of Personality Assessment, 86, 263-272.

Sternberg, R. J. (1988). Mental self-government: A theory of intellectual styles and their development. Human Development, 31 , 197-224.

Sternberg, R. J. (1994). Thinking styles: Theory and assessment at the interface between intelligence and personality. In R. J. Sternberg 
\& P. Ruzgis (Eds.), Personality and intelligence (pp. 169-187). Cambridge, England: Cambridge University Press.

Sternberg, R. J. (1997). Thinking styles. Cambridge, England: Cambridge University Press.

Sternberg, R. J., \& Grigorenko, E. L. (1993). Thinking styles and the gifted. Roeper Review, 16, 122-130.

Sternberg, R. J., \& Grigorenko, E. L. (1995). Styles of thinking in the school. European Journal for High Ability, 6, 201-219.

Sternberg, R. J., \& Grigorenko, E. L. (1997). A capsule history of theory and research on styles. In R. J. Sternberg (Ed.), Thinking styles (pp. 133-147). Cambridge, England: Cambridge University Press.

Sternberg, R. J., \& Grigorenko, E. L. (2001). A capsule history of theory and research on styles. In R. J. Sternberg \& L. F. Zhang (Eds.), Perspectives on thinking, learning, and cognitive styles (pp. 1-21). Mahwah, NJ: Lawrence Erlbaum Associates.

Sternberg, R. J., \& Wagner, R. K. (1992). Thinking Styles Inventory. Unpublished manual, Yale University.

Thompson, B. (2004). Exploratory and confirmatory factor analysis. Washington, DC: American Psychological Association.

Zhang, L. F. (2000). Abilities, academic performance, learning approaches, and thinking styles: A three-culture investigation. Journal of Psychology in Chinese Societies, 1, 123-149.

Zhang, L. F. (2001). Do thinking styles contribute to academic achievement beyond self-rated abilities? The Journal of Psychology, 135, 621-637.

Zhang, L. F. (2002a). Thinking styles: Their relationships with modes of thinking and academic performance. Educational Psychology, $22,331-348$.

Zhang, L. F. (2002b). Thinking styles and cognitive development. The Journal of Genetic Psychology, 163, 179-195.

Zhang, L. F. (2002c). Thinking styles and the big five personality traits. Educational Psychology, 22, 17-31.

Zhang, L. F. (2004). Revisiting the predictive power of thinking styles for academic performance. The Journal of Psychology, 138, 351-370. 
Zhang, L. F. (2006). Thinking styles and the big five personality traits revisited. Personality and Individual Differences, 40, 1177-1187.

Zhang, L. F., \& Postiglione, G. A. (2001). Thinking styles, selfesteem, and socio-economic status. Personality and Individual Differences, 31, 1333-1346.

Zhang, L. F., \& Sachs, J. (1997). Assessing thinking styles in the theory of mental self-government: A Hong Kong validation study. Psychological Reports, 81, 915-928.

Zhang, L. F., \& Sternberg, R. J. (2005). A threefold model of intellectual styles. Educational Psychology Review, 17, 1-53.

\section{End Notes}

1 Data augmentation (DA) is an iterative data simulation technique that involves the alternation of imputation of missing values and Bayesian parameter estimation steps until convergence is reached (Schafer, 2000). The option for single imputation at the end of the DA run, allowing for 1,000 iterations was selected in this case. 